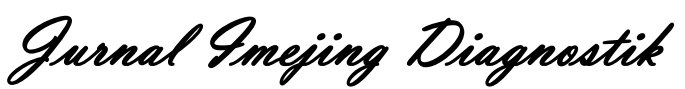

e-ISSN 2621-7457, p-ISSN 2356-301X

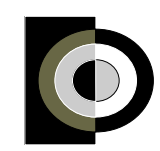

http://ejournal.poltekkes$\underline{\text { smg.ac.id/ojs/index.php/jimed/index }}$

\title{
Perbandingan Informasi Citra Potongan Axial T2 antara Turbo Spin Echo (TSE) dengan Half-Fourier Aquisition Single-Shot Turbo Spin Echo (HASTE) pada Pemeriksaan Magnetic Resonance Cholangiopancreatography (MRCP)
}

\author{
Adilfi Amalia Yuniar ${ }^{1}$, Dartini ${ }^{2}$, Rasyid ${ }^{3}$, Bagus Dwi Handoko ${ }^{4}$, Nanang Sulaksono ${ }^{5}$ \\ 1) KRMT Wongsonegoro Regional General Hospital Semarang, Indonesia \\ 2, 3,4,5) Poltekkes Kemenkes Semarang, Indonesia \\ Corresponding author: Adilfi Amalia Yuniar \\ e-mail: adilfiiflida@gmail.com
}

Received: January 29 ${ }^{\text {th }}, 2021$; Revised: January $30^{\text {th }}, 2021$; Accepted: February $31^{\text {st }}, 2021$

\begin{abstract}
Backgroud: MRCP is a non-invasive imaging examination, which is used for the evaluation of biliary tract, pancreatic duct, and gallbladder. Pulse sequences which can be used to visualize organs in MRCP on T2 weighting is using a fast pulse sequences such as sequences TSE or Haste. The purpose of this research was to knowing the difference image information between T2 axial TSE with Haste and where better to use between the two sequences on axial T2 MRCP examination.

Methods: This type of research is experimental observational approach, it has been carried out in the best MRI 1.5 Tesla at RSU Haji Surabaya. Sample used were 5 patients. Each patient performed two pieces of axial T2 sequences in which the TSE and Haste. Furthermore, the image submitted to the three doctors radiologist to fill out a questionnaire that has been provided to assess the image consisting of the liver, gallbladder, common bile duct (CBD), pancreas, intrahepatic duct and an assessment of the artifacts.

Results: The results of analytical assessment Wilcoxon test, for the entire anatomy with $\rho$ value of 0.002 which means that $\rho<0.05$, and the artifacts show the $\rho$ value of 0.006 , which means $\rho<0.05$. This proves that there are differences in image information between T2 axial TSE with T2 axial Haste the MRCP examination. At each of anatomy, liver has $\rho$ value of $0,071(\rho>0.05)$, gallbladder has $\rho$ value of 0.317 ( $\rho>0.05)$, CBD has $\rho$ value of $0.003(\rho<0.05)$, pancreas has $\rho$ value of $0.014(\rho<0.05)$ and intrahepatic duct has $\rho$ value of $0.004 \quad(\rho<0.05)$. Based on the mean rank statistical test results show sequence Haste better in generating image information on the whole anatomy, but in each of anatomy based on the mean rank of gallbladder both sequences are equally good in showing gallbladder, whereas to display the liver, CBD, pancreas, and intrahepatic duct, the results showed T2 Haste mean rank better, it is because it has the characteristics of high Haste T2 signal intensity and better in reducing motion artifacts.

Conclusion: Wilcoxon test analysis results expressed Ha accepted, meaning that there is a difference between the image information pieces axial T2 TSE with Haste the MRCP examination. The mean rank shows Haste superior to TSE, this is because the artifacts on TSE and therefore contributes to the respondent's assessment, other than that Haste has a high signal intensity so that it can show more clearly ducts.
\end{abstract}

Keywords : MRCP, axial, T2 TSE, T2 Haste, image information

\section{Pendahuluan}

Pemilihan pulsa sekuens yang tepat sangat dibutuhkan untuk menampilkan organ-organ yang kompleks seperti pada abdomen. Salah satu pemeriksaan MRI pada abdomen adalah $M R C P$ (Magnetic Cholangiopancreatography). MRCP merupakan pemeriksaan imaging non invasif, yang digunakan untuk evaluasi traktus biliaris, duktus pankreatikus, dan kandung empedu (Liney, 2006). Pada dasarnya, pemeriksaan MRCP dengan sekuens pembobotan $\mathrm{T} 2$ menangkap intensitas signal yang tinggi dari cairan tubuh, cairan relatif diam atau bergerak lambat yang mengisi dalam lumen seperti duktus pankreatikus dan saluran bilier lainnya tampak hiperintens, jaringan disekitarnya dan 
aliran darah yang intensitas signalnya kecil terlihat hitam (Vitellas et all. 2000).

Pencitraan MRCP yang digunakan dalam bentuk potongan axial, coronal, dan format 3D untuk dapat menampakkan liver, kandung empedu, saluran empedu, dan pankreas (Joseph, 2007). Penggunaan potongan axial untuk mengidentifikasi hepar, pankreas, lesi yang lain dan menampilkan gambaran kandung empedu secara umum untuk membantu akuisisi dari sekuens coronal oblik MRCP (Elster, 2015).

Pulsa sekuens yang dapat digunakan untuk mevisualisasikan organ pada MRCP pada pembobotan T2 adalah menggunakan fast pulse sekuens seperti sekuens TSE (Turbo Spin Echo) atau HASTE (Half-Fourier Aquisition Single-shot Turbo Spin Echo). Kedua sekuens tersebut dapat dilakukan dengan menggunakan teknik breathhold (tahan napas) (Reimer, 2006).

TSE adalah metode menghasilkan gambar spin echo dalam waktu yang relatif singkat. Hal ini dilakukan dengan pemberian pengulangan pulsa RF (radiofrekuensi) $180^{\circ}$. Scan time dapat dikurangi dengan cara melakukan lebih dari satu phase encode per TR (Time Repetition), yang dikenal dengan "echo train" yakni aplikasi beberapa pulsa RF $180^{\circ}$ per TR (Westbrook, 2002). Keuntungan TSE adalah waktu scanning lebih cepat, pengurangan waktu scanning untuk akuisisi gambar high resolution, meningkatkan kualitas gambar dan meningkatkan informasi T2. Kekurangan TSE adalah sensitif terhadap gerakan, meningkatnya motion dan flow artefact, dan pada pembobotan T2 lemak tampak lebih terang karena multiple RF pulsa. TSE digunakan pada pemeriksaan sistem syaraf pusat, pelvis dan muskuloskeletal yang sudah menggantikan penggunaan spin echo. Pada pemeriksaan thorax dan abdomen, dapat menimbulkan artefak pernapasan sehingga diperlukan teknik respiratory compensation seperti breath-hold (Westbrook, 2011).

HASTE merupakan nama alternatif untuk teknik MRI akuisisi fast spin echo dengan scan time lebih cepat. Teknik dasarnya pada pengisisan $k$-space (data MR) yang tidak lengkap (teknik partial fourier). Setengah dari pengisian $k$-space terpenuhi pada satu eksitasi RF atau disebut dengan "single-shot". HASTE dapat dilakukan dengan menggunakan teknik breath-hold. Beberapa keuntungan HASTE adalah waktu akuisisi MR sangat cepat, tidak sensitif terhadap gerakan, mengurangi artefak karena pergerakan dan baik untuk aplikasi yang membutuhkan waktu TE panjang seperti MR myelografi, MR urografi, dan MRCP (Magnetic Resonance Cholangiopancreatography). Kekurangannya gambar yang dihasilkan buram (quite blurry) akibat dari efek filtering T2 karena sejumlah besar pulsa RF (Elmaoglu dan Celik, 2012).

Pada beberapa rumah sakit dengan pesawat MRI 1,5 Tesla menggunaan T2 HASTE untuk irisan axial dan ada beberapa rumah sakit lainnya menggunakan sekuens T2 TSE untuk irisan axialnya pada pemeriksaan MRCP. Sedangkan berdasarkan observasi saat PKL di RSU Haji Surabaya, penggunaan sekuens T2 TSE sebagai sekuens rutin tetapi juga menggunakan sekuens T2 HASTE sebagai sekuens tambahan untuk pasien non kooperatif potongan axial pemeriksaan MRCP.

Tujuan dari penelitian ini adalah untuk mengetahui lebih lanjut perbedaan informasi citra potongan axial T2 antara TSE dengan HASTE dan mana yang lebih baik digunakan antara kedua sekuens tersebut pada potongan axialT2 pemeriksaan MRCP.

\section{Metode}

Populasi dari penelitian ini adalah semua pemeriksaan MRCP, sedangkan sample dari penelitian ini adalah 5 pasien pemeriksaan MRCP dengan potongan axial T2 pada sekuens TSE dan HASTE. Kriteria sample adalah pasien dewasa baik pria maupun wanita dengan kelainan pada sistem billiaris pada pemeriksaan MRCP. Tahapan penelitian yang dilakukan adalah sebagai berikut:

Data yang telah diperoleh kemudian diolah disajikan dalam bentuk tabel kemudian dianalisis secara komputerisasi menggunakan SPSS 20. Dilakukan analisa analitik yaitu dengan uji wilcoxon untuk menilai ada tidaknya perbedaan informasi citra potongan axial T2 antara TSE dengan HASTE pada pemeriksaan MRCP. Analisa analitik dengan tingkat kepercayaan $95 \%$. Sedangkan untuk melihat informasi citra mana yang lebih baik antara penggunaan axial T2 TSE dan HASTE dengan mendeskripsikan mean rank hasil dari analisis uji wilcoxon.

\section{Hasil dan Pembahasan}

\section{Karakteristik Data Penelitian}

Penelitian perbandingan informasi citra potongan axial antara T2 TSE dan T2 Haste dilakukan pada 5 pasien pemeriksaan MRCP yang terdiri dari 3 laki-laki dan 2 perempuan. Pasien yang dalam penelitian ini terdiri atas 5 orang pasien dengan keterangan klinis 1 suspek obstruksi joundice, 3 orang obstruksi joundice, dan 1 orang suspek cholecystitis. Semua pasien 
dilakukan scanning MRCP pada potongan axial T2 TSE dan T2 HASTE menggunakan pesawat MRI Siemens Esensa 1,5 Tesla di RSU Haji Surabaya. Selanjutnya hasil dari kedua pemeriksaan tersebut dinilai secara subjektif dengan membagikan kuisioner kepada 3 responden (dokter radiolog) dengan kualifikasi lebih dari 5 tahun untuk menilai informasi citra pada potongan axial T2 TSE dan Haste pada pemeriksaan MRCP. Informasi citra yang dinilai pada setiap pasien yang dapat menampakkan kriteria anatomi yaitu liver, kandung empedu, common bile duct (CBD), pankreas dan intrahepatic duct serta penilaian terhadap artefak pada slice yang sama setiap sekuens. Berikut contoh citra potongan axial T2 MRCP antara TSE dan Haste:
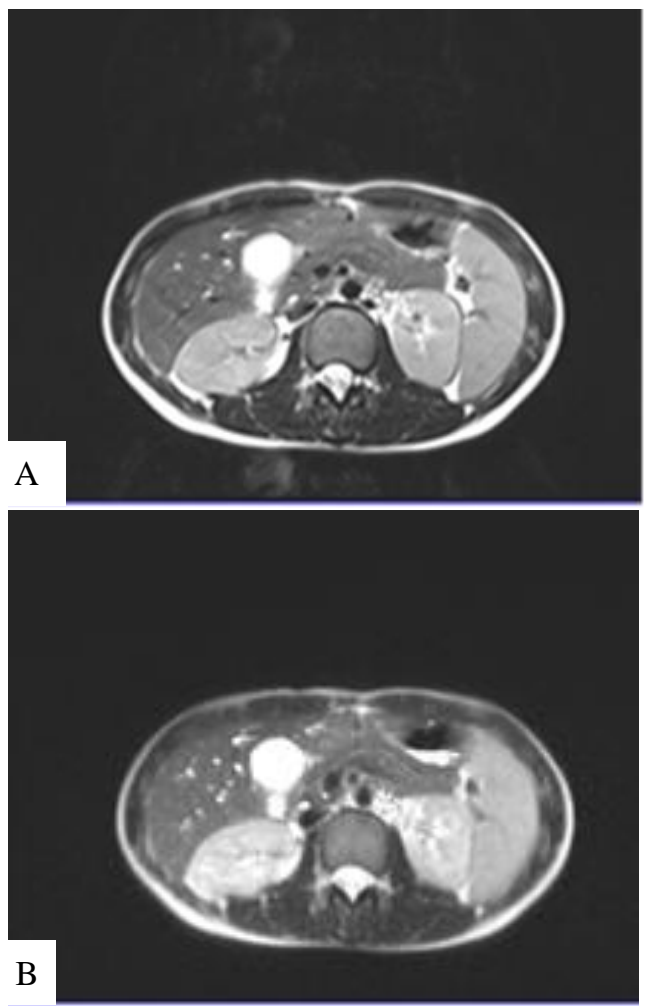

Gambar 1. Potongan Axial T2 MRCP. (A) sekuens TSE dan (B) sekuens Haste

\section{Hasil Uji Statistik Wilcoxon}

Uji statistik wilcoxon dilakukan informasi citra anatomi secara menyeluruh meliputi liver, kandung empedu, common bile duct (CBD), pankreas, dan intrahepatic duct dengan membandingkan nilai total dari perkriteria anatomi yang dapat dinilai pada citra axial T2 MRCP antara sekuens TSE dan Haste. Berdasarkan uji statistik wilcoxon yang telah dilakukan, maka didapatkan hasil sebagai berikut:
Tabel 1. Hasil Uji Statistik Wilcoxon pada Informasi Citra Keseluruhan Anatomi Potongan Axial T2 TSE dan T2 Haste pada Pemeriksaan MRCP

\begin{tabular}{cc}
\hline Informasi citra anatomi & $\rho$ value \\
\hline Axial T2 TSE - axial T2 HASTE & 0,002 \\
\hline
\end{tabular}

Berdasarkan Tabel 1, dengan $\rho$ value $=$ 0,002 artinya $\rho<0,05$. Hal ini berarti ada perbedaan informasi citra keseluruhan anatomi potongan axial T2 antara TSE dengan Haste pada pemeriksaan MRCP.

Untuk memperjelas hasil uji beda informasi citra secara keseluruhan anatomi maka dilakukan uji beda perkriteria anatomi pada potongan axial T2 MRCP yang dapat dilihat pada Tabel 2 sebagai berikut:

Tabel 2. Hasil Uji Statistik Wilcoxon pada Informasi Citra Perkriteria Anatomi Potongan Axial T2 TSE dan T2 Haste pada Pemeriksaan MRCP

\begin{tabular}{lc}
\hline \multicolumn{1}{c}{$\begin{array}{c}\text { Informasi citra perkriteria } \\
\text { anatomi }\end{array}$} & $\rho$ value \\
\hline Liver & 0,071 \\
Kandung empedu & 0,317 \\
Common Bile Duct (CBD) & 0,003 \\
Pankreas & 0,014 \\
Intrahepatic duct & 0,004 \\
\hline
\end{tabular}

Berdasarkan Tabel 2 diatas menunjukkan, unuk kriteria liver $\rho$ value $=0,071$ dan kandung empedu $\rho$ value $=0,317$, dengan $\rho$ value $>0,05$ artinya tidak ada perbedaan informasi citra liver dan kandung empedu pada potongan axial $\mathrm{T} 2$ antara TSE dan Haste. Sedangkan pada citra common bile duct $(\mathrm{CBD}) \rho$ value $=0,003$, pankreas $\rho$ value $=$ 0,014 , dan intrahepatic duct $\rho$ value $=0,004$, dengan $\rho$ value $<0,05$ artinya ada perbedaan informasi citra $\mathrm{CBD}$, pankreas, dan intrahepatic duct pada potongan axial T2 antara TSE dan Haste.

Pada informasi artefak untuk menentukan ada tidaknya perbedaan pada kedua sekuens, maka dapay dilihat pada Tabel 3 sebagai berikut:

Tabel 3. Hasil Uji Statistik Wilcoxon pada Informasi Artefak Potongan Axial T2 TSE dan T2 Haste pada Pemeriksaan MRCP

\begin{tabular}{cc}
\hline Artefak & $\rho$ value \\
\hline $\begin{array}{c}\text { Axial T2 TSE - axial T2 } \\
\text { Haste }\end{array}$ & 0,006 \\
\hline
\end{tabular}

Pada hasil uji statistik wilcoxon untuk artefak, dengan $\rho$ value sebesar 0,006 sehingga 
$\rho<0,05$, artinya ada perbedaan yang signifikan terhadap artefak pada citra potongan axial antara penggunaan T2 TSE dan T2 Haste.

\section{Hasil Mean Rank}

Hasil uji statistik wilcoxon untuk mengetahui penggunaan axial T2 yang lebih baik antara TSE atau Haste pada informasi citra dapat dilihat pada mean rank masing-masing penilaian. Berikut nilai mean rank pada uji statistik non parametrik wilcoxon pada informasi citra potongan axial T2 TSE dan T2 Haste pada pemeriksaan MRCP.

Tabel 4. Mean Rank Uji Wilcoxon pada Informasi Informasi Citra Keseluruhan Anatomi Potongan Axial T2 TSE dan T2 Haste pada Pemeriksaan MRCP

\begin{tabular}{cc}
\hline Informasi Citra Anatomi & Mean rank \\
\hline T2 TSE & 2,00 \\
T2 HASTE & 7,42 \\
\hline
\end{tabular}

Berdasarkan hasil mean rank uji statistik untuk informasi citra keseluruhan anatomi pada Tabel 4, mean rank pada T2 TSE 2,00, sedangkan T2 Haste yaitu 7,42. Hal ini menunjukkan T2 Haste lebih baik untuk informasi citra keseluruhan anatomi. Pada hasil mean rank untuk perkriteria anatomi dapat dilihat pada Tabel 5 sebagai berikut:

Tabel 5. Mean Rank Uji Wilcoxon pada Informasi Citra Perkriteria Anatomi Potongan Axial T2 TSE dan T2 Haste pada Pemeriksaan MRCP

\begin{tabular}{lcc}
\hline $\begin{array}{c}\text { Informasi Citra } \\
\text { Anatomi }\end{array}$ & Sekuens & Mean Rank \\
\hline \multirow{2}{*}{ Liver } & T2 TSE & 6,00 \\
& T2 HASTE & 6,67 \\
\hline \multirow{2}{*}{ Kandung Empedu } & T2 TSE & 2,50 \\
& T2 HASTE & 2,50 \\
\hline \multirow{2}{*}{ Common bile duct } & T2 TSE &, 00 \\
& T2 HASTE & 5,00 \\
\hline \multirow{2}{*}{ Pankreas } & T2 TSE &, 00 \\
& T2 HASTE & 3,50 \\
\multirow{2}{*}{ Intrahepatic duct } & T2 TSE &, 00 \\
& T2 HASTE & 5,00 \\
\hline
\end{tabular}

Berdasarkan hasil mean rank uji wilcoxon, pada informasi citra liver menunjukkan mean rank untuk T2 TSE 6,00 dan T2 Haste 6,67, hal ini menunjukkan baik T2 TSE maupun T2 Haste dapat mevisualisasikan liver, tetapi T2 Haste memiliki mean rank lebih tinggi, artinya T2 Haste lebih baik dalam mevisualisasikan liver. Pada informasi citra kandung empedu menunjukkan mean rank T2 TSE dan Haste sama yaitu 2,50, artinya baik T2 TSE maupun T2 Haste sama-sama baik dalam mevisualisasikan kandung empedu. Common bile duct (CBD) T2 Haste 5,00, pankreas T2 Haste 3,50, dan intrahepatic duct T2 Haste 5,00, sedangkan mean rank untuk T2 TSE pada CBD, pankreas dan intrahepatic duct 0,00 . Artinya T2 Haste lebih baik dalam menampilkan citra CBD, pankreas, dan intrahepatic duct dari T2 TSE.

Sedangkan pada hasil mean rank untuk informasi dalam mengatasi artefak dapat dilihat pada Tabel 6 sebagai berikut:

Tabel 6. Mean Rank Uji Wilcoxon pada Informasi Artefak Potongan Axial T2 TSE dan T2 Haste pada Pemeriksaan MRCP

\begin{tabular}{ccc}
\hline Informasi & Keterangan & Mean Rank \\
\hline Mengatasi & T2 TSE &, 00 \\
Artefak & T2 HASTE & 5,00 \\
\hline
\end{tabular}

Pada Tabel 6 diatas, menunjukkan nilai mean rank T2 Haste lebih tinggi dalam mengatasi artefak yaitu 5,00, artinya T2 Haste lebih baik dalam mengatasi artefak dari T2 TSE.

\section{Hasil Uji Beda}

Pada hasil uji wilcoxon untuk informasi citra keseluruhan anatomi dengan $\rho$ value sebesar 0,002 artinya $\rho<0,05$. Hal ini berarti, ada perbedaan informasi citra keseluruhan anatomi potongan axial T2 antara TSE dengan Haste pada pemeriksaan MRCP.

Menurut peneliti, perbedaan ini disebabkan karena beberapa faktor seperti karakteristik pada masing-masing sekuen dan parameter setiap sekuens. Dalam penelitian ini masing-masing sekuens yang digunakan sudah menjadi parameter dalam pemeriksaan MRCP di RSU Haji Surabaya dalam hal ini potongan axial T2 untuk mendapatkan citra yang baik.

Pada axial T2 TSE waktu yang dibutuhkan lebih lama dari pada axial T2 Haste, yaitu axial T2 TSE membutuhkan waktu 36 detik dengan 2 kali akuisisi sehingga setiap akuisisi pasien harus tahan napas 18 detik setiap akuisisi, sedangkan pada T2 Haste hanya membutuhkan waktu 18 detik jadi pasien hanya tahan napas dalam sekali akuisisi. Waktu akuisisi (scan time) ini dipengaruhi penggunaan Echo Train Length (ETL). Pada axial T2 TSE ETL yang dipakai 31, sedangkan ETL pada axial T2 Haste yang digunakan 256. Menurut Westbrook 2011, semakin besar ETL yang digunakan maka scan time akan semakin pendek, akan tetapi penggunaan ETL yang besar mengakibatkan 
meningkatnya image blurring. Pada fast spin echo beberapa baris $k$-space dapat terpenuhi dengan adanya turbo faktor/ETL sehingga $k$ space akan terisi penuh lebih cepat sehingga dengan terpenuhinya k-space dapat meningkatkan kualitas gambar pada T2, akan tetapi TSE lebih sensitif terhadap gerakan sehingga meningkatnya motion artefak. Sedangkan menurut Elmaoglu dan Celik, 2012, pada T2 Haste dengan teknik dasar pengisian $k$ space yang tidak lengkap (teknik partial fourier) yaitu setengah dari pengisian $k$-space terpenuhi pada satu eksitasi RF dan penggunaan ETL yang sangat panjang menyebabkan keseluruhan persepsi image blurred, penggunaan ETL pada Haste dapat mencapai ratusan sehingga waktu yang diperlukan untuk akuisisi lebih cepat. Meskipun keseluruhan persepsi image blurring tetapi dengan parameter dapat diatur untuk menghasilkan image yang baik terlebih keunggulan Haste adalah tidak sensitif terhadap gerakan sehingga mengurangi motion artefak.

Pengaruh intensitas sinyal terutama cairan dipengaruhi oleh pembobotan $\mathrm{T} 2$ terutama time echo (TE), menurut Westbrook 2011, penggunaan TE yang lebih panjang memberikan waktu T2 decay lebih panjang pada air untuk mempertahankan koherensi transversal. Pada T2 TSE menggunakan TE 82 ms, sedangkan T2 Haste TE 87 ms, meskipun selisih sedikit tetapi berpengaruh terhadap intensitas sinyal yang pada cairan. Selain itu menurut Siemens 2000, Haste memiliki karakteristik menghasilkan kontras pembobotan T2 lebih tinggi, diperkuat dengan penelitian sebelumnya oleh Miyazaki et all, 1996 bahwa Haste mampu menghasilkan high signal intensity pada traktus biliaris, sehingga mampu menampilkan duktus-duktus kecil lebih hiperintens.

Sedangkan pada perkriteria anatomi, berdasarkan uji beda pada anatomi liver dengan $\rho$ value 0,071 yang artinya $\rho>0,05$, hal ini berarti tidak adanya perbedaan yang signifikan pada anatomi liver antara T2 axial TSE dan Haste. Menurut peneliti kedua sekuens samasama mampu mevisualisasikan bentuk anatomi dari liver. Menurut Westbrook 2011, pada TSE pengisisan $\mathrm{k}$-space terisi penuh dengan penggunaan ETL menjadikan waktu scaning cepat untuk akuisisi gambar high resolution, serta mampu meningkatkan kualitas gambar. Penggunaan ETL yang lebih pendek dari Haste juga menjadi keunggulan TSE untuk mengurangi image blurred. Namun, kelemahan dari TSE karena sensitif terhadap gerakan yang menyebabkan timbulnya artefak. Adanya artefak yang ada didalam citra liver potongan axial T2 TSE mempengaruhi hasil penilaian responden. Menurut Westbrook 2011 yang mana kelemahan dari TSE adalah lebih sensitif terhadap gerakan sehingga meningkatnya motion artefak, sedangkan Haste tidak sensitif terhadap gerakan. Adanya artefak ini dapat disebabkan karena ketidak tahanan pasien untuk tahan napas lama atau gerakan peristaltik usus yang berpengaruh terhadap adanya artefak pada liver. Menurut Morelli dkk 2011, menyatakan artefak yang disebabkan karena pergerakan dapat terjadi baik yang terkontrol maupun yang tidak terkontrol dari pasien. Artefak ini terjadi karena adanya deviasi phase atau magnitude dari encoding pada $K$-space. Magnitude errors terjadi ketika sinyal produksi voxel berubah posisi selama aplikasi pulsa RF.

Analisis uji wilcoxon pada kandung empedu dengan $\rho$ value sebesar 0,317 artinya $\rho>0,05$. Hal ini menunjukkan tidak adanya perbedaan yang bermakna antara T2 TSE dan T2 Haste pada potongan axial anatomi kandung empedu. Menurut peneliti, bentuk anatomi dari kandung empedu besar sehingga dapat tervisualisasi dengan baik pada kedua sekuens, karena sama-sama pada pembobotan T2. Menurut Westbrook 2011 pada T2, cairan tampak lebih terang dan dikontrol oleh TE yang panjang sehingga memberikan waktu T2 decay lebih panjang pada air untuk mempertahankan sebagian besar koherensi transversal.

Hasil uji wilcoxon pada anatomi duktusduktus biliaris, dalah penelitian ini yaitu CBD dengan $\rho$ value sebesar 0,003 dan intrahepatic duct dengan $\rho$ value sebesar 0,004 yang berarti $\rho<0,05$, hal ini menunjukkan adanya perbedaan yang signifikan pada anatomi CBD dan intrahepatic duct antara T2 axial TSE dan Haste. Menurut peneliti hal ini karena T2 Haste mampu menghasilkan citra dengan intensitas sinyal yang lebih tinggi pada duktus, karena penggunaan TE yang lebih panjang yaitu 87 ms. Menurut Westbrook 2011 pada T2, cairan tampak lebih terang dan dikontrol oleh TE yang panjang sehingga memberikan waktu T2 decay lebih panjang pada air untuk mempertahankan sebagian besar koherensi transversal. Diperkuat dengan karakteristik dari Haste menurut Siemens 2000, bahwa Haste memiliki karakteristik menghasilkan kontras pada pembobotan T2 lebih tinggi. Dalam penelitian 
Miyazaki et all, 1996 juga menybutkan bahwa Haste mampu menghasilkan high signal intensity pada traktus biliaris, sehingga mampu menampilkan duktus-duktus kecil lebih hiperintens.

Pada analisis uji wilcoxon menyatakan pada pankreas dengan $\rho$ value sebesar 0,014 artinya $\rho<0,05$. Hal ini menunjukkan adanya perbedaan yang bermakna antara T2 TSE dan T2 Haste pada potongan axial anatomi pankreas. Menurut peneliti, kemungkinan karena adanya artefak pada T2 TSE yang mempengaruhi penilaian responden terhadap citra pankreas, sedangkan pada T2 Haste mampu mevisualisasikan citra pankreas tanpa artefak dan mampu menampilkan duktus pankreatikusnya. Menurut Kyoung Ho Lee et al 1998, pada pembobotan T2, TSE mampu mevisualisasikan margin pankreas dengan baik sedangkan pada T2 Haste pankreas blurred tetapi Haste mampu mevisualisasikan pankreas tanpa artefak dan duktus pankreatikus lebih jelas. Menurut Kim et al 1997, menyatakan bahwa Haste-MRCP menghasilkan high-quality image dengan contras to noise ratio yang tinggi sehingga mampu menampakkan duktus pankreatikus.

Penilaian terhadap artefak dengan $\rho$ value sebesar 0,006 berarti $\rho<0,05$, artinya ada perbedaan yang signifikan terhadap artefak pada citra potongan axial antara penggunaan $\mathrm{T} 2$ TSE dan T2 Haste. Menurut peneliti, hal ini sesuai dengan Westbrook 2011 yang mana TSE lebih sensitif terhadap gerakan sehingga meningkatnya motion artefak, sedangkan Haste tidak sensitif terhadap gerakan. Adanya artefak ini yang dapat mempengaruhi penilaian responden terhadap hasil citra pada potongan axial T2 pada pemeriksaan MRCP. Menurut Morelli dkk 2011 menyatakan adanya artefak disebabkan karena pergerakan baik yang terkontrol maupun yang tidak terkontrol dari pasien, artefak ini terjadi karena adanya deviasi phase atau magnitude dari encoding pada $K$ space. Magnitude errors terjadi ketika sinyal produksi voxel berubah posisi selama aplikasi pulsa RF.

5. Hasil penilaian informasi citra yang lebih baik antara penggunaan potongan axial $\mathrm{T} 2$ TSE dengan T2 Haste pada pemeriksaan MRCP

Berdasarkan penilaian dari mean rank pada uji wilcoxon menunjukkan axial T2 Haste lebih baik dalam menghasilkan informasi citra anatomi secara keseluruhan daripada T2 TSE dengan mean rank 7,42. Secara perkriteria untuk anatomi liver dengan mean rank pada T2 Haste 6,67, sedangkan pada T2 TSE selisih sedikit yaitu 6,00 menunjukkan T2 Haste lebih baik dalam menampilkan citra liver. Menurut peneliti hal ini disebabkan kemungkinan karena adanya artefak pada liver T2 TSE, artefak yang terjadi akibat gerakan seperti gerak peristaltik usus dan pernapasan. Menurut Westbrook 2011, T2 TSE memiliki kelemahan sensitif terhadap gerak.

Pada kandung empedu antara T2 TSE dan T2 Haste memiliki mean rank yang sama, artinya kedua sekuens tersebut sama-sama baik dalam menampilkan citra kandung empedu pada potongan axial T2 pemeriksaan MRCP. Sedangkan untuk $C B D$, pankreas dan intrahepatic duct pada T2 Haste memiliki mean rank yang lebih tinggi dari pada T2 TSE. Hal ini karena T2 Haste memiliki karakteristik high signal intensity sehingga mampu mevisualisasikan duktus-duktus biliaris, termasuk mampu menampilkan diktus pankreatikus pada pankreas tanpa motion artefak. Sesuai menurut Miyazaki et all, 1996 menybutkan bahwa Haste mampu menghasilkanhigh signal intensity pada traktus biliaris, sehingga mampu menampilkan duktusduktus kecil lebih hiperintens.

Penilaian terhadap artefak menunjukkan nilai mean rank T2 Haste lebih tinggi dalam mengatasi artefak yaitu 5,00, artinya T2 Haste lebih baik dalam mengatasi artefak dari T2 TSE.Hal ini sesuai dengan Westbrook 2011, bahwa T2 Haste tidak sensitif terhadap gerakan, sehingga tidak terjadi motion artefak. Menurut Morelli dkk 2011, menyatakan artefak yang disebabkan karena pergerakan dapat terjadi baik yang terkontrol maupun yang tidak terkontrol dari pasien. Artefak ini terjadi karena adanya deviasi phase atau magnitude dari encoding pada $K$-space. Magnitude errors terjadi ketika sinyal produksi voxel berubah posisi selama aplikasi pulsa RF.

\section{Simpulan}

Hasil analisa uji wilcoxon untuk keseluruhan anatomi menunjukkan $\rho$ value 0,002 artinya $\rho<$ 0,05 , sedangkan untuk artefak menunjukkan $\rho$ value 0,006 artinya $\rho<0,05$. Dari kedua informasi tersebut menunjukkan $\rho<0,05$, dengan demikian hasil uji hipotesis menyatakan Ha diterima, artinya ada perbedaan informasi citra potongan axial antara T2 TSE dengan T2 HASTE pada 
pemeriksaan MRCP. Pada hasil uji beda perkriteria anatomi menunjukkan bahwa untuk liver dan kandung empedu tidak ada perbedaan yang signifikan, dan pada common bile duct, pankreas, dan intrahepatic duct terdapat perbedaan yang signifikan antara T2 TSE dan T2 Haste pada potongan axial MRCP.

Hasil mean rank uji wilcoxon menunjukkan nilai informasi citra axial T2 Haste 7,42 sedangkan axial T2 TSE 2,00, hal ini menunjukkan T2 Haste lebih baik dalam menampilkan informasi citra potongan axial T2 pada MRCP. Sedangkan pada mean rank setiap kriteria menunjukkan bahwa untuk liver mean rank pada T2 Haste lebih tinggi daripada T2 TSE, hal ini kemungkinan karena adanya artefak pada liver. Pada kandung empedu memiliki mean rank yang sama artinya kedua sekuens sama-sama baik dalam mevisualisasikan kandung empedu. Sedangkan pada Common bile duct, pankreas, dan intrahepatic duct menunjukan mean rank pada T2 Haste lebih baik daripada T2 TSE. Hal ini disebabkan karena pada Haste memiliki karakteristik menghasilkan intensitas sinyal tinggi, sehingga lebih hiperintens pada duktus-duktus biliaris seperti CBD, intrahepatic duct nampak jelas dan menampilkan pankreas tanpa motion artefak serta dapat menampakkan duktus pankreatikusnya. Di lihat dari mean rank uji wilcoxon mengenai artefak, T2 Haste memiliki mean rank 5,00 dalam mengatasi artefak, artinya T2 Haste lebih baik dalam mengatasi artefak daripada T2 TSE.

Sebaiknya pada pemeriksaan MRCP untuk potongan axial T2, Haste dapat digunakan langsung untuk pasien non kooperatif tanpa harus menggunakan TSE terlebih dahulu, tetapi untuk pasien yang kooperatif dapat menggunakan TSE dengan pengaturan parameter yang sesuai sehingga waktu yang diperlukan singkat untuk menghindari artefak pada potongan axial T2 MRCP.

\section{Daftar Pustaka}

Elmaoglu, Muhammed and Azim Celik. 2012. MRI Handbook: MR Physics, Patient Positioning, and Protocols.Springer: Germany

Elster, Allen D. 2015. Question and Answers in MRI. http://mriquestions.com/fse- parameters.html, diakses tanggal 1 Maret 2016

Morelli, John N., et al, 2011. An Image-based Approach to Understanding the Physics of $M R$ Artifacts. radiographics.rsna.org, diakses tanggal 2 April 2016

Miyazaki, Toshiyuki et al, 1996. MR Cholangiopancreatography Using HASTE (Half-Fourier Acquisation Single-shot Turbo Spin-Echo) Sequences. Ajronline.org, diakses tanggal 1 April 2016

Joseph. 2007. Radiography of Billiary System. www.ceessentials.net.html, diakses tanggal 1 April 2016

Kim, T.K et al. 1997. $M R$ Cholangiopancreatography: Comparison Between Half-Fourier Acquisition Single Shot Turbo Spin Echo and Two Dimensional Turbo Spin Echo Pulse Sequences. www.ncbi.nlm.nih.gov, diakses tanggal 2 Maret 2016

Liney, Gary. 2006. MRI In Clinical Practice. Springer: Singapore

Lee, Ho Kyoung et al. 1998. MRI of Normal Pancreas: Comparison of T2 Weighted Pulse Sequences Using Turbo Spin Echo, Turbo Spin Echo with Fat Suppression, Haste and Haste with Fat Supression. J Korean Radiol Soc. Korean

Reimer,P, Paul M.Parzel, F.A Stichnoth (Eds). 2006. Clinical MR Imaging A Practical Approach. Springer: Germany

Siemens. 2000. Siemens magnetom basic description MR basic principles training documen. Erlangen. Germany

Vitellas et all. 2000. MR Cholangiopancreatography of Bile and Prancreatic Duct Abnormalities With Emphasis On The Single-Shot Fast Spin Echo Technique. http://radiographics.rsna.org/content/20/4/9 39. abstract, diakses tanggal 2 Maret 2016

Westbrook. C. 2002. MRI at a Glance. Blackwell Science Ltd: United Kingdom

Westbrook, Catherine, Carolyn Kaut B, John Talbot. 2011. MRI In Practice. Fourth Edition. Wiley-Blackwell. USA 